\title{
D0I: https://dx.doi.org/10.21879/faeeba2358-0194.2021.v30.n63.p80-94 REPRESENTAÇÕES SIMBÓLICAS DA
EDUCAÇÃO FEMININA EM JORNAL
ESCOLAR DO ENSINO SECUNDÁRIO
}

\author{
Cintia Medeiros Robles Aguiar* \\ Secretaria Municipal de Educação de Campo Grande-MS \\ https://orcid.org/0000-0002-9177-9122 \\ Jacira Helena do Valle Pereira Assis** \\ Universidade Federal de Mato Grosso do Sul \\ https://orcid.org/0000-0002-4539-6462
}

\section{RESUMO}

Tem-se como objeto de análise o jornal escolar ABC Literário, produzido por e para estudantes secundaristas. 0 objetivo é compreender como a divisão entre os sexos está presente em estado objetivado e em estado incorporado, nos corpos e nos habitus dos agentes, agindo como representações da educação formal feminina por uma perspectiva histórico-sociológica pautada em Chartier e Bourdieu. Utiliza-se a Análise de Conteúdo como técnica de pesquisa. Os resultados apontam que ao discutir a representação da mulher, encontramos a representação dominante da figura masculina, instaurada como caráter produtivo das relações de poder. Essas representações não são meras descrições, elas constituem e constroem realidades à medida que produzem efeito sobre os agentes. Assim, a relação de dominação entre homens e mulheres se estabelece em todos os espaços, não só na família, mas também no universo escolar, e dá visualidade à permanência da estrutura da relação de dominação entre homens e mulheres. Por fim, indica-se adotar a partir desta leitura uma atitude vigilante e contínua no sentido de procurar desestabilizar as divisões e problematizar a conformidade com o "natural".

Palavras-chave: educação de mulheres; imprensa estudantil; formação de estudantes secundaristas; dominação simbólica.

\section{ABSTRACT \\ SYMBOLIC REPRESENTATIONS OF FEMALE EDUCATION IN A SCHOOL JOURNAL OF SECONDARY EDUCATION}

The object of analysis is the ABC Literary school newspaper, produced by and for high school students. The objective is to understand how the division between the sexes is present in an objectified state and in an incorporated state, in the bodies and habitus of agents, acting as representations of formal

\footnotetext{
Mestra em Educação pela Universidade Federal de Mato Grosso do Sul (UFMS). Professora da Educação Básica na Secretaria Municipal de Educação de Campo Grande/MS. Campo Grande, Mato Grosso do Sul. Brasil. E-mail: cintia.robles@outlook.com

** Doutora em Educação pela Universidade de São Paulo (USP). Professora titular da Universidade Federal de Mato Grosso do Sul (UFMS). Campo Grande, Mato Grosso do Sul. Brasil. E-mail: jpereira.dou@terra.com.br
} 
female education from a historical-sociological perspective based on Chartier and Bourdieu. Content Analysis is used as a research technique. The results show that when discussing the representation of women, we find the dominant representation of the male figure, established as a productive character of power relations. These representations are not mere descriptions, they constitute and build realities as they produce an effect on agents. Thus, the relationship of domination between men and women is established in all spaces, not only in the family, but also in the school universe, and gives visibility to the permanence of the structure of the relationship of domination between men and women. Finally, it is recommended to adopt, based on this reading, a vigilant and continuous attitude to try to destabilize the divisions and problematize conformity with the "natural".

Keywords: education of women; student press; training secondary school students; symbolic domination.

\section{RESUMEN}

\section{REPRESENTACIONES SIMBÓLICAS DE LA EDUCACIÓN FEMENINA EN UNA REVISTA ESCOLAR DE EDUCACIÓN SECUNDARIA}

El objeto de análisis es el periódico escolar ABC literario, elaborado por y para estudiantes de secundaria. El objetivo es comprender cómo la división entre sexos está presente en un estado objetivado y en un estado incorporado, en los cuerpos y habitus de los agentes, actuando como representaciones de la educación formal femenina desde una perspectiva histórico-sociológica basada en Chartier y Bourdieu. El análisis de contenido se utiliza como técnica de investigación. Los resultados muestran que, al discutir la representación de la mujer, encontramos la representación dominante de la figura masculina, establecida como un carácter productivo de las relaciones de poder. Estas representaciones no son meras descripciones, constituyen y construyen realidades a medida que producen un efecto sobre los agentes. Así, la relación de dominación entre hombres y mujeres se establece en todos los espacios, no solo en la familia, sino también en el universo escolar, y da visibilidad a la permanencia de la estructura de la relación de dominación entre hombres y mujeres. Finalmente, a partir de esta lectura, se recomienda adoptar una actitud vigilante y continua para intentar desestabilizar las divisiones y problematizar la conformidad con lo "natural".

Palabras-clave: educación de la mujer; prensa de los estudiantes; formación de estudiantes de secundaria; dominación simbólica.

\section{Introdução}

0 jornal escolar $A B C$ Literário, ${ }^{1}$ produzido por e para estudantes secundaristas ${ }^{2}$ do Centro

10 jornal passou por mudança de nomenclatura: as edições de 1961 e 1962 são nomeadas de $O A B C$, e as de 1968 de ABC Literário.

2 Todo estudante que cursou o ensino secundário - por ensino secundário compreende-se "[...] a etapa que dá continuidade à escolarização formal após o término do ensino primário e que antecede e prepara o estudante para o ingresso no ensino superior" (ASSIS, 2015, p. 15). Importante ressaltar que a mulher que é objeto de discussão neste texto é a estudante secundarista, adolescente que necessariamente tem no mínimo 11 anos para estudantes do diurno e 14 anos para estudantes do noturno. 
Educacional Osvaldo Cruz de Dourados, ${ }^{3}$ situado no antigo sul de Mato Grosso (indiviso), na década de 1960, é o objeto e fonte principal desta pesquisa. As inserções do impresso enquanto fonte e objeto de investigação são possíveis em virtude das mudanças paradigmáticas que ocorreram, principalmente a partir das últimas décadas do século XX, com a expansão de objetos historiográficos e suas diferentes possibilidades de tratamento pela perspectiva da Nova História Cultural.

Com o objetivo de compreender como a divisão entre os sexos está presente em estado objetivado, em todo o mundo social, e em estado incorporado nos corpos, e nos habitus dos agentes, agindo como representações da educação formal feminina ofertada no ensino secundário do sul de Mato Grosso, propõe-se realizar as possíveis aproximações ao objeto nas bases e referências teóricas da Nova História Cultural, representada por Roger Chartier, vinculada a uma investigação sociológica pautada na Teoria da Prática de Pierre Bourdieu.

Uma discussão sobre representações da educação feminina constituída a partir do estudo de impressos estudantis se torna relevante ao apontar não só elementos da individualidade, mas abranger conhecimentos específicos das estruturas sociais. Nesse sentido, o estudo dos impressos estudantis é proeminente no domínio teórico entre a História e a Sociologia por contribuir na compreensão crítica das condições de existência do agente social, aqui em referência ao estudante secundarista, as estruturas e mecanismos sociais e seus efeitos sobre o conjunto da categoria da qual ele faz parte.

Os instrumentos de investigação dos documentos na aplicação das leituras analíticas empreendidas foram realizados por meio da Análise de Conteúdo com fundamento em Laurence Bardin (2016). As fontes interrogadas

3 É o resultado da união das seguintes escolas: Escola Primária Princesa Isabel (1958), Colégio Osvaldo Cruz de Dourados (1954), o Colégio Comercial Santos Dumont (1961) - que ofertava o curso ginasial de Comércio e o curso Técnico em Contabilidade - e a Escola Normal Olavo Bilac (1965) (CENTRO EDUCACIONAL OSVALDO CRUZ DE DOURADOS, 1970). são documentos oficiais, iconografias, o acervo do Osvaldo Cruz doado ao Centro de Documentação Regional da Faculdade de Ciências Humanas da Universidade Federal da Grande Dourados (CDR/UFGD), imprensa periódica, livros de memória, entrevistas e relatos.

0 recorte temporal foi delimitado na década de 1960, por ser o tempo histórico de produção do objeto deste estudo, ou seja, do jornal escolar $A B C$ Literário, que se constitui de 13 exemplares, a saber: $\mathrm{n}^{\text {os }} 2,4,6$ e 7, datados de 1961, equivalentes aos meses de maio, junho, setembro e outubro; $\mathrm{n}^{\text {os }} 8$ a 10 , respectivamente de março a maio de 1962; e n ${ }^{\text {os }} 1$ a 6, referentes aos meses de março, abril, maio (com dois números publicados $n^{\text {os }} 3$ e 4 ), agosto e setembro de 1968.

Na congruência de reconstruir historicamente nuances da formação educacional de mulheres no ensino secundário, elaboramos os seguintes tópicos: "Tempos de Capanema: o ensino secundário feminino", no qual buscamos nos aproximar do papel e da função da escola (de ensino secundário feminino) em analogia aos preceitos de incorporação da dominação cunhada por Bourdieu e Chartier; "Um campo de lutas, disputas e concorrências: práticas de dominação na educação feminina”, em que enfatizamos práticas de relação entre os sexos que ocorriam no ginásio e como estas formam uma representação social da existência feminina na sociedade da década de 1960 no contexto do sul de Mato Grosso.

\section{Nos tempos de Capanema: as representações do ensino secundário feminino no Brasil}

[...] o ministro da Educação dedica um item especial de seu discurso à educação feminina. Segundo ele, os poderes públicos, na organização dos estabelecimentos de ensino, deveriam 'considerar diversamente o homem e a mulher'. Mesmo reconhecendo que, 'no mundo moderno, um e outro são chamados à mesma quantidade de esforço pela obra comum', ele reafirma que 
a educação a ser dada à mulher deve diferir daquela dada ao homem, 'na medida em que diferem os destinos que a Providência lhes deu'. Segundo Capanema, 'se o homem deve ser preparado com a têmpera militar, para os negócios e as lutas, a educação feminina terá outra finalidade, que é o preparo para a vida do lar'. Para o ministro, 'é a mulher que funda e conserva a família, como é também por suas mãos que a família se destrói'. Ora, a família é 'a base da organização social', estando por isso 'colocada sob a proteção especial do estado'. A este compete preparar convenientemente a mulher para a sua 'grave missão', através da educação que lhe é ministrada. Por esta razão, a educação feminina exige dos poderes públicos 'cuidados e medidas especiais'. (HORTA, 2010, p. 55-56, grifo nosso).

Iniciamos este tópico com o excerto da obra de Horta (2010) sobre o pensamento de um expoente da história educacional no plano nacional, o ministro da Educação Gustavo Capanema, e sua adesão e disposição em colocar o sistema educacional brasileiro a serviço da ideologia do Estado Novo - em discurso por ele pronunciado na comemoração do centenário do Colégio Pedro II, realizado no Teatro Municipal do Rio de Janeiro, na presença de Getúlio Vargas, no dia 2 de dezembro de 1937 - para elucidar as questões ligadas especificamente à educação das mulheres neste período histórico, uma formação que cumpre um papel e uma função bem específicas na sociedade.

Voltamos o olhar para o discurso proferido por Gustavo Capanema em 1937, que tomou forma e conteúdo na Lei Orgânica do Ensino Secundário, Decreto-Lei 4.244, de 9 de abril de 1942 (BRASIL, 1942), ou seja, para como a existência da mulher era concebida e quais papéis sociais lhe eram destinados. Convém destacarmos que as práticas simbólicas que são aptas a conferir legitimidade social às coisas e pessoas se passam "no" e "em" torno do Osvaldo Cruz, logo representam apenas um caso particular de todo um rito social.

O então estado de Mato Grosso, no período delimitado, era um estado predominantemente rural e localizado longe dos grandes centros populacionais, o que facilitou a expansão do ensino secundário pela iniciativa privada. Apesar de se constituir em um capitalismo periférico com condições bem específicas, o Centro Educacional Osvaldo Cruz era uma instituição particular, o que em si já se apresentava como um fator de distinção social, nos autorizando a considerá-lo, desse modo, como uma instituição destinada aos grupos das elites daquele espaço social.

A instituição - grosso modo - atendia aos preceitos do Decreto-Lei 4.244/1942 (BRASIL, 1942), quais sejam: um tipo de ensino para a formação de elites condutoras do país oferecido quase que exclusivamente pela iniciativa privada, conforme analisam Norberto Dallabrida, Dayane Mezuram Trevizoli e Letícia Vieira (2013, p. 11), etapa que manteve "[...] o caráter segregador e excludente" deste nível de ensino, bem como o "[...] predomínio de acesso ao ensino secundário para as classes economicamente favorecidas”, garantindo, assim, “[...] um nível de preparação intelectual adequado à formação da elite condutora do país" que propiciava a inculcação do "habitus de elite" nos jovens pertencentes às classes com maior volume de capital econômico.

Com um ensino custeado e de acesso restrito a uma camada pequena da população, inferimos que, quando tratamos de uma elite local, nos referimos a uma fração muito específica dessa elite, pois se tratava de uma elite localizada em um município pequeno, com menos de $10 \%$ da população do estado, em passos de crescimento, localizado próximo à fronteira de um país pobre (Paraguai) e no interior do estado, muito distante da capital, sem polos industriais ou ferrovia e com uma fração ainda muito pequena da sociedade com mobilidade de capital econômico.

Feita as aproximações ao contexto local, parte-se do pressuposto cunhado por Louro (1997) de que desde seus primórdios a instituição escolar exerceu uma ação distintiva, sendo incumbida de separar os indivíduos - tornando aqueles que nela entravam distintos dos outros, 
os que a ela não tinham acesso. Dividiu também internamente os que nela estavam, por meio de inúmeros meios de classificação, ordenamento e hierarquização: “[...] a escola que nos foi legada pela sociedade ocidental moderna começou por separar adultos de crianças, católicos de protestantes. Ela também se fez diferente para os ricos e para os pobres e ela imediatamente separou os meninos das meninas." (LOURO, 1997, p. 57).

A posição exposta corrobora com Bourdieu (2012), autor de quem incorporamos a forma de esquemas de percepção e de apreciação, as estruturas históricas da ordem masculina, e não há dúvidas de que o que está sendo proposto, objetiva e explicitamente, pela instituição escolar é a constituição de indivíduos masculinos e femininos heterossexuais - nos padrões da sociedade em que a escola se inscreve. Essa divisão entre os sexos

[...] parece estar 'na ordem das coisas', como se diz por vezes para falar do que é normal, natural, a ponto de ser inevitável: ela está presente, ao mesmo tempo, em estado objetivado nas coisas (na casa, por exemplo, cujas partes são todas 'sexuadas'), em todo o mundo social e, em estado incorporado, nos corpos e nos habitus dos agentes, funcionando como sistemas de esquemas de percepção, de pensamento e de ação. (BOURDIEU, 2012, p. 17).

A força da ordem masculina se evidencia no estado objetivado e incorporado, pois dispensa justificação, a visão androcêntrica se impõe como neutra e não tem necessidade de se enunciar em discursos que visem a legitimá-la. Para pensar a questão da educação feminina e como esses esquemas de percepção e apreciação foram concebidos pelos estudantes secundaristas na década de 1960, é relevante registrar que a educação feminina era somente uma parte de um todo muito mais amplo.

Poucos anos antes da instalação do Osvaldo Cruz, em 1954, houve um intenso debate que envolveu políticos e intelectuais católicos e protestantes em torno de um anteprojeto denominado "Estatuto da família", proposto por volta de 1939 a 1942 por Gustavo Capanema, que, grosso modo, buscava o aumento da população e consolidar e proteger a família em sua estrutura tradicional.

Além dessas medidas voltadas especificamente para o núcleo familiar, existiam várias outras com repercussões mais profundas. Uma delas se referia ao mercado de trabalho. 0 estatuto previa que os pais da família tivessem preferência em investidura e acesso a todos os cargos e funções públicas, na competição com os solteiros ou casados sem filhos, exceto em cargos de responsabilidade, como se pode observar em alguns trechos de seus artigos:

O estado educará ou fará educar a infância e a juventude para a família. Devem os homens ser educados de modo a que se tornem plenamente aptos para a responsabilidade de chefes de família. Às mulheres será dada uma educação que as torne afeiçoadas ao casamento, desejosas da maternidade, competentes para a criação dos filhos e capazes de administração da casa. (Art.13).

0 estado adotará medidas que possibilitem a progressiva restrição da admissão de mulheres nos empregos públicos e privados. Não poderão as mulheres ser admitidas senão aos empregos próprios da natureza feminina e dentro dos estritos limites da conveniência familiar. (Art. 14). (LOURO; MEYER, 1993, p. 51).

Essa restrição ao trabalho feminino estava ligada à tese da mais absoluta divisão de papéis e de responsabilidade dentro do casamento. Isto se refletia, também, na área da educação, como podemos observar no Art. 14., portanto, esta divisão de papéis precisava, evidentemente, ser garantida e protegida. Para isto, seria necessário fortalecer a comunidade familiar, portanto, a questão da formação da mulher e de seu papel na família já era pauta no contexto político brasileiro antes mesmo da existência do Osvaldo Cruz, e essas questões alavancam a construção de uma identidade feminina enraizada na interiorização pelas mulheres, de normas enunciadas pelos discursos masculinos.

De acordo com Bourdieu (2012), o Estado ratifica e reforça as prescrições de um patriar- 
cado privado com as de um patriarcado público, inscrito nas instituições encarregadas de gerir e regulamentar a existência cotidiana da unidade doméstica, que faz da família patriarcal o princípio e o modelo tanto de ordem social como ordem moral, fundamentada na preeminência absoluta dos homens em relação às mulheres.

O Estado moderno se inscreveu no direito de família, "[...] especialmente nas regras que definem o estado civil dos cidadãos, todos os princípios fundamentais da visão androcêntrica" (BOURDIEU, 2012, p. 105). Nesta perspectiva, nosso olhar se volta sobre os dispositivos que asseguram a eficácia dessa violência simbólica, nos discursos e práticas,

[...] manifestos em registros múltiplos, que garantem (ou devem garantir) que as mulheres consintam nas representações dominantes da diferença entre os sexos: desta forma [...] a inculcação escolar dos papéis sociais, a exclusão da esfera pública etc. Longe de afastar do 'real' e de só indicar figuras do imaginário masculino, as representações da inferioridade feminina, incansavelmente repetidas e mostradas, se inscrevem nos pensamentos e nos corpos de umas e de outros. (CHARTIER, 1995, p. 40).

Destacamos dentre estes dispositivos o tratamento especial que a Lei Orgânica do Ensino Secundário (BRASIL, 1942) reservou às mulheres. As prescrições especiais para a educação das mulheres (não dos homens) recomendava sua realização em estabelecimentos exclusivamente femininos; nos casos dos estabelecimentos frequentados por homens e mulheres, a educação delas deveria se dar em classes exclusivamente femininas, sendo este preceito obrigatório e só deixando de vigorar com autorização do Mistério da Educação.

Incluiu-se, na terceira e quarta série do curso ginasial e em todas as séries dos cursos clássico e científico, a disciplina de economia doméstica e a orientação metodológica dos programas tiveram como objetivo a "natureza da personalidade feminina", ou seja, a "missão" da mulher dentro do lar.
Definir a submissão imposta às mulheres como uma violência simbólica nos ajuda a compreender como a relação de dominação - que é uma relação histórica, cultural e linguisticamente construída, e que se insere no sistema educacional por meio de distintas estratégias, visando à imposição da dominação masculina - é construída no campo da educação, a qual discutir-se-á no próximo tópico.

\section{Um campo de lutas, disputas e concorrências: práticas de dominação na educação feminina}

Este tópico tem como princípio norteador o conceito de luta de representações. Por luta de representações compreendemos, conforme Chartier (1991, p. 183), que

[...] uma dupla via abre-se: uma que pensa a construção das identidades sociais como resultando sempre de uma relação de força entre as representações impostas pelos que detêm o poder de classificar e de nomear e a definição, de aceitação ou de resistência, que cada comunidade produz de si mesma; outra que considera o recorte social objetivado como a tradução do crédito conferido à representação que cada grupo dá de si mesmo, logo a sua capacidade de fazer reconhecer sua existência a partir de uma demonstração de unidade.

Assim, a apropriação das representações no meio social gera tensões entre indivíduos e grupos sociais distintos, e a disputa pelo sentido de determinado fato ou personagem histórico ocasiona as lutas de representações. Antes de nos debruçarmos pelo caminho das lutas de representação, alguns pontos demandam ser pontuados: o primeiro está no contexto histórico em que o jornal foi publicizado e circulou entre essas meninas e esses meninos. Estamos em um período histórico intenso, a década de 1960 passa pela Guerra Fria, corrida espacial, a defesa dos direitos civis dos negros nos Estados Unidos, Golpe Civil-Militar no Brasil, movimento estudantil, AI-5, até a chegada do homem à lua. 
E a mulheres não estão alheias a todos esses acontecimentos. A pressão do movimento das mulheres aprova no Congresso Nacional o fim da tutela dos maridos sobre suas esposas (BRASIL, 1962), surge a pílula anticoncepcional e o movimento pelos direitos civis das mulheres começam a tomar forma, força e efervescência, que vai perder terreno com a ditatura militar, e é neste contexto histórico que essas meninas estão em formação.

Portanto, é importante destacar que, no contexto que elas viviam, em um estado predominantemente rural, longe dos grandes centros, não existia uma problematização destas questões, o papel e a função da mulher eram tidos como natural, por isso consideramos que estas lutas não são apenas culturais, são políticas, e giram em torno da busca pela legitimação de determinado significado.

Os movimentos populares e as organizações feministas foram e são fundamentais para discutirmos essas questões atualmente, para nos aproximarmos de como essas questões eram pensadas nas políticas educacionais, como isso se efetiva na escola, portanto discutiremos os paradoxos que regem a relação entre os sexos e como esse cenário de lutas, disputas e concorrências se constroem.

Constitui um paradoxo o fato de que, embora presente em todos os dispositivos de escolarização, a preocupação com a sexualidade geralmente não é apresentada de forma aberta. Em entrevista concedida ao Jornal Diário MS, o diretor do Osvaldo Cruz relatou que:

$\mathrm{Na}$ época meninos e meninas não podiam estudar numa mesma escola e o Osvaldo Cruz quebrou essa tradição, o que representou um grande escândalo. 0 preconceito foi ainda maior quando o colégio passou a oferecer aulas no período noturno, pois as mulheres eram proibidas de estudarem ou saírem à noite. (LINS, 2003, p. 8, grifo nosso).

Não sabemos ao certo se ou quando "essa tradição" foi literalmente quebrada ou em que ano o ginásio passou a oferecer aulas noturnas para mulheres, contudo, na distribuição de turmas de 1960, observamos que ainda havia uma sala exclusivamente feminina na $1^{\circ}$ série, como se pode observar na Figura 1.

Figura 1 - Área das salas de aula do GOC e a distribuição das turmas (1960)

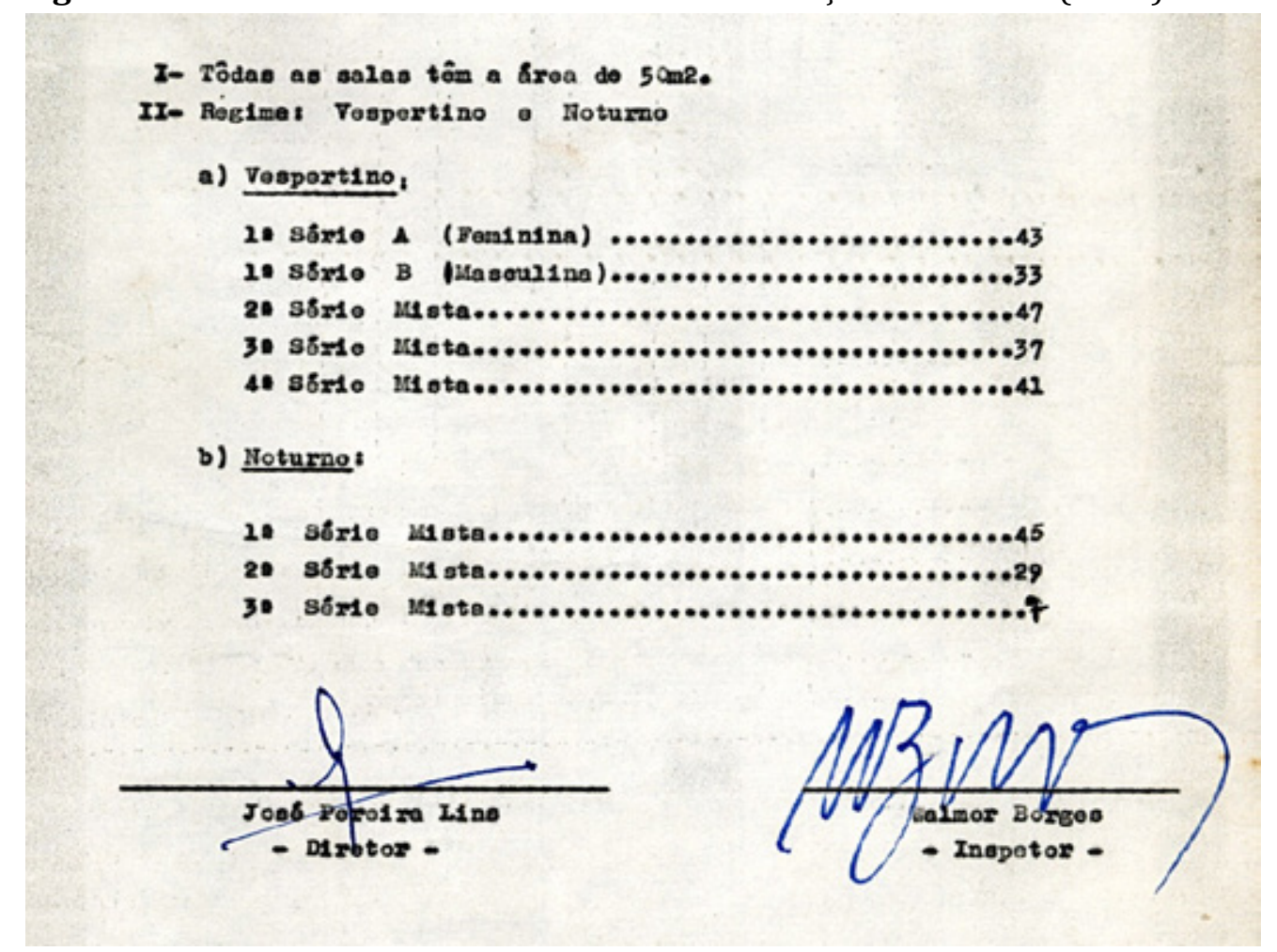

Fonte: Centro Educacional Osvaldo Cruz de Dourados (1960a). 
Observamos que o discurso do Diretor é no sentido de que o fim da segregação entre homens e mulheres era um diferencial, quando, na prática, os mecanismos de separação estavam em pleno funcionamento. Nessa perspectiva, reconhecemos que o ginásio não apenas reproduziu ou refletiu as concepções de gênero e sexualidade que circulavam na sociedade, mas que ele próprio as produziu.

0 "preconceito" em relação à educação feminina ofertada no período noturno, mencionado pelo Prof. Lins na entrevista, nos parece correto, pois apenas 12 mulheres das 118 matriculadas estudavam à noite, o que pode ser mensurado pela Figura 2.

Figura 2 - Quadro geral de matrículas do GOC (1960)

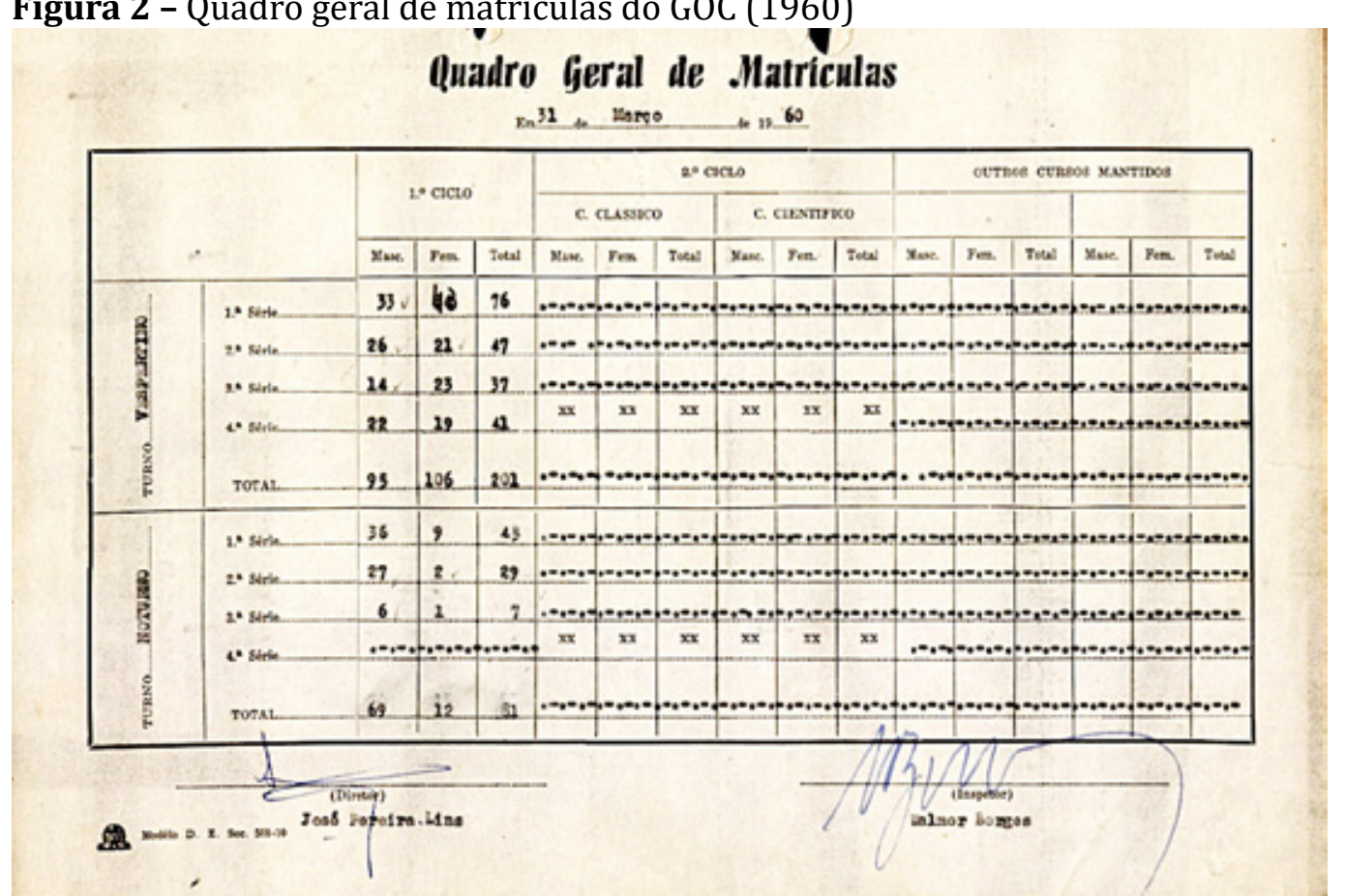

Fonte: Centro Educacional Osvaldo Cruz de Dourados (1960b).

Embora tímidos avanços em uma educação igualitária tenham sido realizados, os registros do Livro de portarias internas do Osvaldo Cruz (CENTRO EDUCACIONAL OSVALDO CRUZ DE DOURADOS, 1967) nos forneceram indícios de que, independentemente de as turmas serem ou não mistas, a separação entre meninos e meninas era uma prática, ora implícita, ora explicita, contudo recorrente. A Portaria n 6/1967 determinava uma linha divisória da área comum do ginásio entre homens e mulheres:

Portaria no 6/67: 0 diretor do estabelecimento, no uso de suas atribuições, a fim de evitar futuros incidentes, determina que nenhum aluno do sexo masculino, antes, durante e depois do recreio ultrapasse a linha divisória do pátio que lhes está reservada, ou seja, a linha reta que vai da área direita do estabelecimento a extremidade do muro nos fundos. No caso de qualquer transgressão haverá a penas que de mister. Para que ninguém alegue ignorância seja esta lida perante todos os alunos e executada.

Dourados, 8 de junho de 1967. (CENTRO EDUCACIONAL OSVALDO CRUZ DE DOURADOS, 1967, p. 9).

Em umas das publicações da coluna "O pátio do colégio", essa divisória também foi mencionada: "Começa a ficar manjado aquele casal de namorados que tôdas as noites se debruça na cerquinha divisória do pátio ou se 'encontra' num dos esteios da cantina. Apelido que lhe deram: 'Os Corcundas do GOC.'” (O PÁTIO..., 1968, p. 3-4).

Podemos perceber que a linha divisória já existia antes de 1967, e a Portaria de no 6 só 
reforçou a ordem para seu devido cumprimento. E em 1968, não só uma linha os separavam, há uma cerca que impede o contato entre os estudantes do sexo masculino e feminino. Se em algumas áreas da instituição a constituição da identidade de gênero pareceu, muitas vezes, ser feita por meio dos discursos implícitos, nas aulas de Educação Física esse processo foi mais explícito e evidente. A Educação Física nos pareceu ser uma área na qual as resistências ao trabalho integrado persistiam, ou melhor, em que as resistências provavelmente se renovavam, a partir de outras argumentações ou de novas teorizações.

Na relação do corpo docente em exercício no ano de 1960, a única disciplina em que havia um professor do sexo masculino para turmas masculinas e uma professora do sexo feminino para turmas femininas, desde a $1 \stackrel{\text { a }}{\text { até a }} 4^{\underline{a}}$ série, era a de Educação Física. Concepções como essas possivelmente impediam que fossem propostas às meninas as realizações de jogos ou atividades físicas tidos como masculinos, ou, na melhor das hipóteses, as obrigavam a se ajustarem '[...] à 'debilidade' feminina. Mais uma vez se consagra a ideia de que o feminino é um desvio construído a partir do masculino." (LOURO, 1997, p. 73-74).

0 quantitativo de matrículas femininas nos chamou atenção, apesar de toda uma estrutura social de exclusão, de uma representação coletiva que as compreendia apenas como "a rainha do lar", aliada a uma cultura cristã de inferioridade da mulher, como podemos mensurar em alguns trechos do jornal $A B C$ Literário:

A direção dêste jornal fará circular, no próximo dia 12 uma edição extra de <<ABC Literário >>, alusiva à data magna da Rainha do Lar. (DIA DAS..., 1968, p. 4, grifo nosso).

Já ouviram falar que os sábios erram? Pois os que seguem erraram:

A. KOTZEBVE: Onde pode encontrar a humanidade templo mais belo do que o coração da mulher?

F. F. ROUSECU: A mulher é a mais bela metade do mundo.
A. MUSSET: A mulher é a mais bela das aves que existem na terra.

LAMARTINE: Há sempre uma mulher na origem de todas as grandes coisas.

CICERO: Sem as mulheres os homens conversariam com os deuses.

$* * *$

Um filósofo bem-humorado disse: 0 casamento é um porto onde dois navios se encontram. Um marido franzino muito maltratado ao ler isso disse com seus botões: EU devo ter encontrado um navio de guerra (sic!). (BENGALA..., 1962, p. 4).

Notamos que, ao mesmo tempo que as mulheres tinham o direito à educação, elas eram redirecionadas ao seu principal objetivo: cuidar do lar. Contudo, elas persistiram, somavam $42 \%$ das matrículas da instituição, saíam de suas casas para estudar com homens e disputavam com eles os lugares de destaque. Em menor número, sabemos, estudavam à noite, contrariando toda uma cultura machista, e estavam presentes nas representações estudantis e na composição da administração do grêmio estudantil. Ser mulher, independentemente de classe, capitais ou tempo histórico, significava e continua significando resistência.

Nesse sentido, fazemos uma crítica aos apontamentos de Moreira e Rodrigues (2017) quando essas autoras questionam a ausência da participação feminina nos engajamentos estudantis partidários, enfatizando que as matérias a este respeito são assinadas majoritariamente por homens. Além disso, as referidas autoras observaram que quando a chapa apresentada para as eleições da ADES, pelo grêmio estudantil Coelho Neto, tinha na presidência a figura de uma mulher, careceu, por parte do grêmio, nota de esclarecimento.

[...] É sempre difícil de se encontrar elementos capazes de desempenhar a função para a qual foi eleita, dentro de uma certa responsabilidade e enterêsse, dái o atrazo com que lançamos a referida chapa. Deve ter causado estranheza o fato de termos apresentado uma moça para presidir a nossa Associação, entretanto é algo natural. Temos na Srta. Iracema M. Martins, como é do 
conhecimento de todos, uma pessoa capacitada, de responsabilidade e de espírito empreendedor. E assim são os demais componentes. [...] são elementos que estão sempre em contato conosco e bem podemos fazer boas conclusões, baseando nos inúmeros serviços e capacidades administrativas demonstrados praticamente, em benefício dos estudantes douradenses. (A CHAPA..., 1961, p. 4).

A nota destaca a estranheza de muitos na indicação de uma mulher para presidir a associação. Nesta direção, três pontos que foram enfatizados na nota são merecedores de destaque: 1) Que a escolha seria algo "natural" (não deveria haver estranheza em indicar uma pessoa com competência para o cargo, mesmo sendo uma mulher), o que demonstra a definição dos papéis masculinos e femininos na sociedade, e que romper com eles requer explicações; 2) Alguns adjetivos são mencionados, que visavam à qualificação da moça à presidência da Associação (a escolha das palavras é deverás interessante: pessoa capacitada, de responsabilidade e de espírito empreendedor), indicando a necessidade de qualificar uma mulher para desempenhar uma função que não foi dedicada a ela historicamente; 3) Os demais membros da chapa são citados nome a nome, implicitamente demonstrando que a moça não está sozinha, que tem uma equipe tão capacitada quanto ela e que, apesar de ela presidir, há muitos homens desempenhando funções importantes.

Moreira e Rodrigues (2017) ignoraram que há de se considerar que tal prática deve ser avaliada como algo audacioso à época, considerando, por exemplo, que o próprio jornal elucidava um discurso implícito em que a mulher ocupava papéis específicos, como a edição de colunas que tratavam de "mexericos", de moda e de literatura.

Temos como suposição que a estranheza pela presença feminina na presidência da associação pode ter sido um dos motivos de a "Chapa Progressista" ter perdido as eleições. No entanto, destacamos que as mulheres ocupavam espaços distintos, seja na composição da administração do grêmio e do Jornal estudantil, presidindo a campanha e o conselho deliberativo de uma chapa nas eleições para representação estudantil, seja escrevendo e ousando indicar autoria em seus textos, como podemos observar no Quadro 1.

Quadro 1 - Espaço ocupado pelas mulheres na instituição de ensino (1960)

\begin{tabular}{|l|l|}
\hline MULHERES & ESPAÇOS OCUPADOS E FUNÇÕES DESEMPENHADAS \\
\hline Iracema M. Martins & $\begin{array}{l}\text { Tesoureira do Grêmio Estudantil, compôs a administração do Jornal, pre- } \\
\text { sidiu a Chapa Progressista para eleição da ADES e foi colunista de gênero } \\
\text { diversional no jornal. }\end{array}$ \\
\hline Maria Elei V. Dienes & Secretária do Grêmio Estudantil e compôs a administração do Jornal. \\
\hline Elza Garcia Gonçalves & Escritora de poesias (Normalista egressa do Osvaldo Cruz) \\
\hline Eronilde de Matos Souza & Escritora de textos de cunho político \\
\hline Eunice de Oliveira & Escritora de gênero opinativo \\
\hline Gedalva Olive & Colunista de gênero informativo \\
\hline Maria Lucia Meireles & Colunista de Crônica Social \\
\hline Neusa Barbosa & Escritora de Poemas \\
\hline Odete Fernandes & Colunista de gênero diversional \\
\hline Carmélia Ferreira Guimarães & Colunista de gênero diversional \\
\hline Stael Maria Fernandes & Colunista de gênero diversional \\
\hline Teresa M. Toyoko & Escritora (em datas comemorativas) \\
\hline Aglaé Terezinha Pereira & Escritora de crônicas (estudante de Direito em Ponta Grossa/PR). \\
\hline Clélia Echeverria & Presidiu o Conselho Fiscal da Chapa Progressista para eleição da ADES \\
\hline
\end{tabular}

Fonte: Elaborado pelas autoras deste artigo com base em matérias do Jornal $O A B C$. 
Convém destacarmos que o Quadro 1 é um extrato advindo das informações contidas nas edições do Jornal ABC Literário, o espaço ocupado por essas e outras estudantes pode ter sido muito maior. É notório que a presença feminina era minoria, mas neste momento histórico e dadas todas as implicações culturais, faz-se necessário o reconhecimento que ter mulheres com voz significou um engajamento político estudantil feminino valioso.

Compreendemos que romper com esse processo de produção do "homem viril" - provedor e ocupante dos cargos públicos - e da "mulher feminina" - frágil e do lar - é uma questão em vias de construção permanente. 0 trabalho de reprodução esteve garantido à época por três instâncias principais, quais sejam: a família, a igreja e a escola, que objetivamente orquestradas tinham em comum o fato de agirem sobre as estruturas inconscientes. Corroboramos com Bourdieu (2012, p. 103-104) que,

É, sem dúvida, à família que cabe o papel principal na reprodução da dominação e da visão masculinas; é na família que se impõe a experiência precoce da divisão sexual do trabalho e da representação legítima dessa divisão, garantida pelo direito e inscrita na linguagem. [...] a Escola, mesmo quando já liberta da tutela da Igreja, continua a transmitir os pressupostos da representação patriarcal (baseada na homologia entre a relação homem/mulher e a relação adulto/criança) e sobretudo, talvez, os que estão inscritos em suas próprias estruturas hierárquicas, todas sexualmente conotadas, entre as diferentes escolas [...], isto é, entre as maneiras de ser e as maneiras de ver, de se ver, de se representarem as próprias aptidões e inclinações, em suma, tudo aquilo que contribui para traçar não só os destinos sociais como também a intimidade das imagens de si mesmo.

De fato, a cultura acadêmica veiculada pela instituição escolar nunca deixou de encaminhar modos de pensar e modelos arcaicos, mas ela foi, ao mesmo tempo, um dos princípios mais decisivos na mudança nas relações entre os sexos, devido às contradições que nela ocorreu e às que ela própria introduziu. 0 aumento do acesso das mulheres à instrução e, correlativamente, à independência econômica, bem como a mudança nas estruturas familiares, "[...] contribuem para quebrar a doxa e ampliar o espaço das possibilidades em matéria de sexualidade" (BOURDIEU, 2012, p. 108), e assim os modelos tradicionais de masculino e feminino foram sendo afetados e levaram a uma modificação importante da posição da mulher.

Como esse foi um cenário de disputas, lutas e concorrências, as representações do feminino estavam em conflito o tempo todo. Identificamos estratégias disciplinares para o governamento dos corpos a partir de padrões estéticos e de feminilidade. Embora os padrões estéticos sejam mutáveis e definidos de acordo com o contexto histórico e cultural, a preocupação atingia as meninas, como podemos observar nesta crônica social:

Sendo êste o nosso primeiro número de crônica, temos pouco o que dizer sôbre a nossa juventude escolar. Vimos no domingo passado, na saída da segunda missa às nove horas da manhã, as gentis senhoritas Jane Giolando, numa bela saia 'band-lon', que a deixava encantadora, Marly Martins, num delicado conjunto saia e blusa, que exaltava tôda sua beleza, Danilda Zocolaro num bonito vestido estampado, colorido como sua mocidade, Sônia Barbosa muito bem trajada, Giselda Brandão sempre elegante, Carmélia Guimarães, num delicado conjunto 'bouché', estava muito bonita, Maria Eneide sempre distribuindo alegria, Ramona Bergottini, radiante e com sua novidade em penteados. Bem minhas caras colegas, até o próximo número com mais novidade para vocês. (CRÔNICA..., 1962, p. 1).

Quem ganhou destaque foram somente as "moças bem vestidas", que escolheram a peça de roupa correta, que estavam bem alinhadas e penteadas. Um ponto de destaque é que essas moças foram "flagradas" na saída da missa, portanto, os/as estudantes do Osvaldo Cruz eram reconhecidos(as) dentro e fora da instituição, percebidos(as) pelos seus modos de agir, de falar, de se portar, pela maneira como se vestiam, independentemente do lugar que frequentassem. Outra notícia que se pautou em padrões estéticos e de feminilidade foi o evento de coroação da rainha dos estudantes: 
Com grande animação foi coroada a Rainha dos Estudantes, a Srta. Olmira Barroso, aluna do Ginásio Osvaldo Cruz de Dourados. Foi um acontecimento de enorme satisfação e alegria para nós estudantes, vermos, com éxito, o nosso esfôrço no sentido de escolher a nossa representante e tornando assim nossa árdua vida de estudante, num campo florido e cheio de encantos. Recebeu a faixa de Princeza dos Estudantes, a graciosa Srta. Neusa Barbosa, também aluna do G.O.C. e que nos honra com a amizade e compania. Este jornal, representando os estudantes, felicita as duas encantadoras jovens, desejando-lhes felicidades. Aos senhores Pais igualmente os nossos parabéns. (COROADA..., 1961, p. 1).

O evento, que contou com a participação de estudantes, familiares e da sociedade douradense, tratou-se aparentemente de um concurso em que as estudantes do Osvaldo Cruz mencionadas na citação acima foram as vencedoras, uma coroada rainha e outra recebendo a faixa de princesa, ambas consideradas pelos estudantes as representantes do grupo estudantil, assim os "títulos" indicam serem as mais destacadas entre as estudantes. Este tipo de solenidade promovia a interação entre os estudantes e destacava os princípios escola- res, geralmente o que se era valorizado era a beleza estudantil em todos os aspectos: físico, apresentação e vestimenta.

Os pais foram parabenizados ao final da notícia, o que nos faz inferir que estavam envolvidos no evento, reforçando a imagem de parceria entre os pais e a instituição. Uma vez que os concursos valorizavam um tipo de beleza, e como em qualquer momento histórico nem todos se enquadravam nesses padrões, entendemos que deter e mobilizar capitais seria a chave para se destacar nesses eventos.

O que não está explicito é que o corpo feminino parecia estar sempre colocado em exibição, devendo sempre fazer sucesso em qualquer lugar, e que essas imagens, desde o "flagra" na saída da missa até a escolha da rainha e da princesa dos estudantes, não eram neutras. Elas produziam significados, estabeleciam hierarquias (quem é a melhor ou pior, mais bonita ou mais feia etc.), estabelecendo e reforçando relações de poder desiguais. As eleitas "rainha" e "princesa" saíram no desfile cívico em carro alegórico, do qual temos o registro do ano de 1965, na Figura 3.

Figura 3 - Desfile Cívico - Rainha e Princesa dos estudantes em carro alegórico (1965)
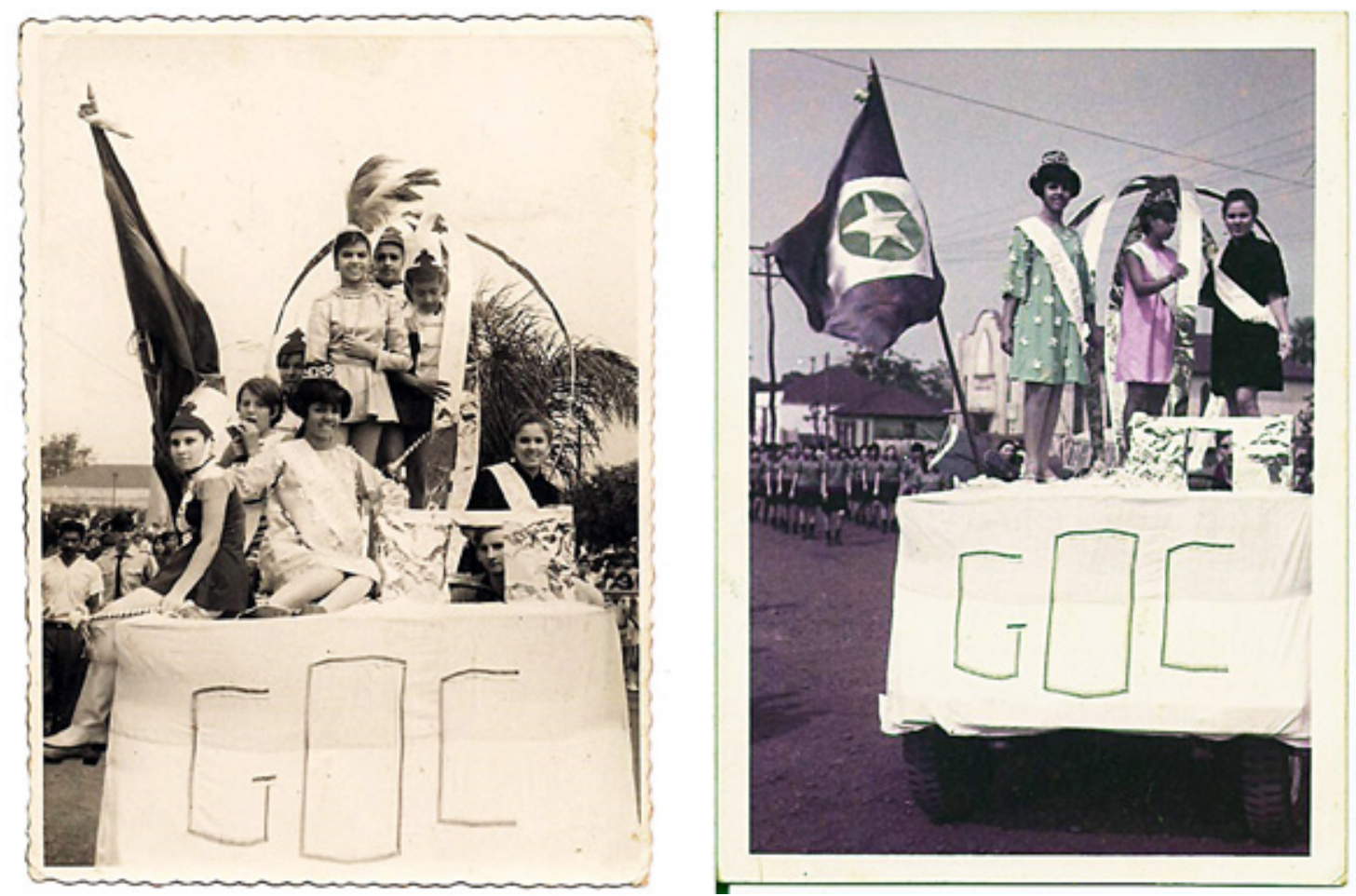

Fonte: Centro Educacional Osvaldo Cruz de Dourados (1965). 
Essas imagens expressam representações de feminilidades deste grupo social, determinando um ideal feminino heterossexual, ligado à fragilidade, à passividade e à "graça". Assim, ao mesmo tempo em que avançam em alguns preceitos ocupando novos espaços e rompendo com o modelo tradicional de feminino, não se excluíam afastamentos e manipulações como "o efeito da beleza".

Por fim, compreendemos que a concepção de vida social (sentido do jogo) na relação entre sexo e gênero foi construída na polarização masculino/feminino, "polarização que nos impede de contemplar as distinções no interior de cada um desses polos e a 'comunalidade' que pode atravessá-los” (LOURO, 1997, p. 78). Essa polarização foi alicerçada pela instituição escolar por meio da separação entre meninos e meninas nas atividades escolares, grupos de estudo ou competições e práticas cotidianas. Por outro lado, ela também construiu uma série de situações que representaram um "cruzamento de fronteiras", ou seja, situações em que as fronteiras ou os limites entre os gêneros foram atravessados.

Com base em Louro (1997), nos damos conta de que as preocupações e a vigilância em relação à sexualidade não se restringiram aos estudantes, mas a todas as pessoas, incluindo os adultos que conviveram na escola, como os professores de Educação Física, por exemplo. A vigilância e o controle da sexualidade orientaram, fundamentalmente, o alcance da "normalidade", representada pela heterossexualidade, na qual a identidade masculina e a identidade feminina se ajustaram às representações hegemônicas de cada gênero e da sociedade patriarcal.

\section{Considerações finais}

Pistas sobre as formas pelas quais as mulheres eram concebidas e quais papéis lhes eram determinados foram corroboradas neste texto. Desvelamos que o campo da educação feminina possui diversos dispositivos que asseguraram a eficácia de uma violência simbólica em seus discursos e práticas, bem como estratégias, ainda que inconscientemente, de uma dominação masculina.

A proposição de discutir a representação feminina se torna pertinente quando compreendemos que é por meio da representação dominante da figura masculina - heterossexual, chefe de família (uma família nuclear, a correta e desejável) - que se instaura o caráter produtivo das relações de poder. Essas representações não são meras descrições, elas constituem e constroem realidades à medida que produzem efeito sobre os agentes. Os homens são educados a continuarem a dominar o espaço público e a área de poder, sobretudo o econômico, e sobre a produção, ao passo que as mulheres ficam destinadas, predominantemente, ao espaço privado ou espécies de extensões deste espaço.

As estruturas de divisão sexual parecem determinar as estratégias dos dispositivos de vigilância e controle e o sentido do jogo, fazendo introjetar a visão dominante que permite à dominação masculina se perpetuar nesta estratégia, ainda que haja transformações dos modos de produção econômica. Assim, a relação de dominação entre homens e mulheres, tal como ela se estabelece em todos os espaços e subespaços sociais, isto é, não só na família, mas também no universo escolar, dá visualidade à permanência da estrutura da relação de dominação entre homens e mulheres ligadas a este momento histórico e às suas posições no espaço social.

A escola encontra-se no fundamento da dominação, contribui para a sua reprodução e realiza de maneira particularmente marcante um trabalho de dominação simbólica, bem como suas estratégias visam a impor, ainda que inconscientemente, a dominação masculina. Nessa perspectiva, reconhecemos que o ginásio não apenas reproduziu ou refletiu as concepções de gênero e sexualidade que circulavam na sociedade, mas também contribuiu para produzi-las. 
Esse trabalho de produção e reprodução foi garantido por três instâncias principais, quais sejam, a família, a igreja e a escola, e uma instância secundária, o jornal escolar $A B C$ Literário, que objetivamente orquestradas tinham em comum o fato de agirem sobre as estruturas inconscientes, organizando os esquemas de reconhecimento e apreciações, ou seja, as representações socias.

Sem alimentar uma postura reducionista ou ingênua - que supõe ser possível transformar toda a sociedade a partir da escola ou supõe ser possível eliminar as relações de poder em qualquer instância -, a partir desse estudo reconhece-se como as relações de dominação masculina construíram representações simbólicas em toda uma classe estudantil, representação essa que perdura até a atualidade. Indica-se adotar a partir desta leitura uma atitude vigilante e contínua no sentido de procurar desestabilizar as divisões e problematizar a conformidade com o "natural". Isso implica disposição e capacidade para interferir nos jogos de poder e perceber a instituição escolar e o impresso estudantil, na verdade de seus usos sociais, como fundamentos da dominação e da legitimação da dominação.

\section{REFERÊNCIAS}

A CHAPA progressista. $\mathbf{O}$ ABC - Órgão do Grêmio Estudantil Coelho Neto, Dourados, MT, p. 4, out. 1961.

ASSIS, Jacira Helena do Vale Pereira. Ensino secundário no sul de Mato Grosso no século XX: itinerários de pesquisa com fontes memorialísticas. In: ASSIS, Jacira Helena do Valle Pereira; SILVA, Alice Felisberto da (org.). Memórias do ensino secundário no sul de Mato Grosso no século XX. Campo Grande, MS: Ed. Oeste, 2015. p. 23-48.

BARDIN, Laurence. Análise de conteúdo. Tradução Luís Antero Reto, Augusto Pinheiro. 3. reimp. da 1. ed. São Paulo: Edições 70, 2016.

BENGALA Mágica. O ABC - Órgão do Grêmio Estudantil Coelho Neto, Dourados, MT, p. 4, maio 1962.

BOURDIEU, Pierre. A dominação masculina.
Tradução Maria Helena Kühner. 11. ed. Rio de Janeiro: Bertrand Brasil, 2012.

BRASIL. Decreto-Lei 4.244, de 9 de abril de 1942. Lei orgânica do ensino secundário. Diário Oficial da União: seção 1, Rio de Janeiro, DF, ano LXXXI, n. 94, p. 6717, 24 abr. 1942. Disponível em: http://www2.camara.gov.br. Acesso em: 10 mar. 2016.

BRASIL. Lei no 4.121, de 27 de agosto de 1962. Dispõe sobre a situação jurídica da mulher casada. Diário Oficial da União: seção 1, Capital Federal, DF, ano CI, n. 168, p. 1, 03 set. 1962. Disponível em: https://www.jusbrasil.com.br/ diarios/2941087/pg-1-secao-1-diario-oficial-dauniao-dou-de-03-09-1962/pdfView. Acesso em: 20 ago. 2021.

CENTRO EDUCACIONAL OSVALDO CRUZ DE DOURADOS. Álbum de fotografia: desfiles cívicos. Coleção Osvaldo Cruz de Dourados. Centro de Documentação Regional FCH/UFGD. CD-ROM. Dourados, MS, 1965.

CENTRO EDUCACIONAL OSVALDO CRUZ DE DOURADOS. Livro de portarias internas. Coleção Osvaldo Cruz de Dourados. Centro de Documentação Regional FCH/UFGD. Caixa 18. Dourados, MS, 1967.

CENTRO EDUCACIONAL OSVALDO CRUZ DE DOURADOS. Regimento interno. Coleção Osvaldo Cruz de Dourados. Centro de Documentação Regional FCH/UFGD. Caixa 11. Dourados, MT, 1970.

CENTRO EDUCACIONAL OSVALDO CRUZ DE DOURADOS. Relatório de verificação prévia: área das salas de aulas e distribuição das turmas. Coleção Osvaldo Cruz de Dourados. Centro de Documentação Regional FCH/UFGD. Caixa 1. Dourados, MS, 1960a.

CENTRO EDUCACIONAL OSVALDO CRUZ DE DOURADOS. Relatório de verificação prévia: quadro geral de matrículas. Coleção Osvaldo Cruz de Dourados. Centro de Documentação Regional FCH/UFGD. Caixa 1. Dourados, MS, 1960b.

CHARTIER, Roger. Diferenças entre os sexos e dominação simbólica (nota crítica). Cadernos Pagu, n. 4, p. 37-47, 1995. Disponível em: https://periodicos.sbu.unicamp.br/ojs/index.php/ cadpagu/article/view/1761/1816. Acesso em: 18 out. 2019.

CHARTIER, Roger. 0 mundo como representação. Estudos Avançados, São Paulo, v. 5, n. 11, p. 173191, abr. 1991. Disponível em: http://www.scielo. br/scielo.php?script=sci_arttext\&pid=S0103- 
40141991000100010\&lng=en\&nrm=iso. Acesso em: 24 out. 2019.

COROADA a rainha dos estudantes. $\mathbf{O}$ ABC - Órgão do Grêmio Estudantil Coelho Neto, Dourados, MT, p. 1 , set. 1961.

CRÔNICA social. O ABC - Órgão do Grêmio Estudantil Coelho Neto, Dourados, MT, p. 1, abr. 1962.

DALLABRIDA, Norberto; TREVIZOLI, Dayane Mezuram; VIEIRA, Letícia. As mudanças experimentadas pela cultura escolar do ensino secundário devido a implementação da reforma Capanema de 1942 e da Lei de Diretrizes e Bases da Educação de 1961. In: COLÓQUIO ENSINO MÉDIO, HISTÓRIA E CIDADANIA, 8., 2013, Florianópolis. Anais [...]. Florianópolis: UDESC/FAED/Grupo de Pesquisa Sociedade, Memória e Educação, 2013. v. 3, n. 3, p. 1-13. Disponível em: http://www. revistas.udesc.br/index.php/EnsinoMedio/article/ view/4066/2787. Acesso em: 01 fev. 2019.

DIA DAS mães. ABC Literário - Órgão de Iniciação Literária do Grêmio Estudantil Osvaldo Cruz, Dourados, MT, p. 4, abr. 1968.

HORTA, José Silvério Baia. Gustavo Capanema. Recife: Fundação Joaquim Nabuco: Massangana, 2010.
LINS, José Pereira. Escola Osvaldo Cruz é desativada. Jornal Diário MS, Dourados, MT, 2003. Variedades, p. 8.

LOURO, Guacira Lopes. Gênero, sexualidade e educação: uma perspectiva pós-estruturalista. Petrópolis, RJ: Vozes, 1997.

LOURO, Guacira Lopes; MEYER, Dagmar. A escolarização do doméstico. A construção de uma escola técnica feminina (1946-1970). Cadernos de Pesquisa, São Paulo, n. 87, p. 45-57, nov. 1993. Disponível em: http://publicacoes.fcc.org.br/ojs/ index.php/cp/article/view/1896/1863. Acesso em: 20 nov. 2019.

MOREIRA, Kênia Hilda; RODRIGUES, Eglem Oliveira Passone. $O$ Ginásio Osvaldo Cruz de Dourados nas páginas do jornal estudantil $\mathrm{ABC}$ : ensino secundário no sul de Mato Grosso nos anos 1960. Série-Estudos, Campo Grande, MS, v. 22, n. 46, p. 113-136, set./dez. 2017. Disponível em: http://www.serieestudos.ucdb.br/index.php/serie-estudos/article/ view/999. Acesso em: 21 dez. 2018.

O PÁTIO do colégio. ABC Literário - Órgão de Iniciação Literária do Grêmio Estudantil Osvaldo Cruz, Dourados, MT, p. 3-4, set. 1968.

Recebido em: 13/10/2020

Aprovado em: 03/08/2021

(c) $\mathbf{E}$ EY-NC Este é um artigo publicado em acesso aberto sob uma licença Creative Commons. 